\title{
Analysis of Factors for Predicting Survival in Soft-tissue Sarcoma with Metastatic Disease at Initial Presentation
}

\author{
TOMOKI NAKAMURA ${ }^{1}$, HIROHISA KATAGIRI ${ }^{2}$, YOJI SHIDO ${ }^{3}$, SHUNSUKE HAMADA ${ }^{4}$, \\ KENJI YAMADA ${ }^{5}$, AKIHITO NAGANO ${ }^{6}$, SATOSHI YAMADA ${ }^{7}$, SATOSHI TSUKUSHI ${ }^{8}$, \\ DAISUKE ISHIMURA $^{9}$, AKIHIKO MATSUMINE ${ }^{1}$, AKIHIRO SUDO ${ }^{1}$ and YOSHIHIRO NISHIDA ${ }^{4}$ \\ ${ }^{1}$ Department of Orthopaedic Surgery, Mie Graduate School of Medicine, Tsu, Japan; \\ ${ }^{2}$ Division of Orthopaedic Oncology, Sizuoka Cancer Hospital, Nagaizumi, Japan; \\ ${ }^{3}$ Departmemt of Orthopaedic Surgery, Hamamatsu Medical University, Hamamatsu, Japan; \\ ${ }^{4}$ Department of Orthopaedic Surgery, Nagoya University Graduate School of Medicine, Nagoya, Japan; \\ ${ }^{5}$ Department of Orthopedic Surgery, Aichi Cancer Center, Aichi Hospital, Okazaki, Japan; \\ ${ }^{6}$ Department of Orthopedic Surgery, Gifu University Graduate School of Medicine, Gifu, Japan; \\ ${ }^{7}$ Department of Orthopedic Surgery, Graduate School of Medical Sciences, Nagoya City University, Nagoya, Japan; \\ ${ }^{8}$ Department of Orthopaedic Surgery, Aichi Cancer Center, Nagoya, Japan; \\ ${ }^{9}$ Department of Orthopaedic Surgery, School of Medicine, Fujita Health University, Toyoake, Japan
}

\begin{abstract}
Background/Aim: We aimed to confirm predictors of survival in soft-tissue sarcoma (STS) patients with metastatic disease at initial presentation in 9 Institutions under the Tokai Musculoskeletal Oncology Consortium. Patients and Methods: Between 2008 and 2013, 47 STS patients with metastatic disease at initial presentation were referred for treatment. The mean follow-up duration was 24 months. Results: The mean C-reactive protein (CRP) levels were $2.47 \mathrm{mg} / \mathrm{dl}$. The mean hemoglobin and albumin levels were $13.1 \mathrm{~g} / \mathrm{dl}$ and $4.1 \mathrm{~g} / \mathrm{dl}$, respectively. Hemoglobin and albumin levels were significantly correlated with CRP levels. In the multivariate analysis, age, CRP levels, and albumin levels were confirmed as independent prognostic factors for disease-specific survival (DSS). Conclusion: We suggest that the measurements of CRP and albumin levels are a useful method of identifying STS patients with metastasis at initial presentation that have poor prognosis.
\end{abstract}

In patients with soft-tissue sarcoma (STS), the presence of systemic inflammation has been associated with a poor

Correspondence to: Dr. Tomoki Nakamura, Department of Orthopaedic Surgery, Mie University Graduate School of Medicine, 2-174, Edobashi, Tsu-city, Mie, 514-8507, Japan. Tel: +81592315022, Fax: +81-592315211, e-mail: tomoki66@clin.medic.mieu.ac.jp

Key Words: Soft tissue sarcoma, C-reactive protein, albumin, metastasis. prognosis (1-8). Elevations of C-reactive protein (CRP) levels, hypoalbuminemia and anemia have been correlated with histological tumor grade and size in patients with nonmetastatic STS (1-6). Those factors have also been significantly correlated with poor disease-specific survival, metastasis-free survival, and local control, suggesting that those are clinical indicators that reflect the aggressive behavior of tumors (1-6). However, only $18-22 \%$ of patients with non-metastatic STS had elevated CRP levels or/and hypoabluminemia $(1,6)$. We hypothesized that the patients with STS who have metastatic disease at initial presentation are more likely to have systemic inflammation because these patients have poor prognosis due to the aggressiveness of tumors. Furthermore, recently, a prognostic tool using the combination of CRP levels and albumin levels, CRP/albumin ratio (CAR) and Glasgow prognostic score (GPS), was reported as an independent prognostic marker for survival in several types of cancer $(1,9-12)$. The aim of this study was to determine whether the blood markers are useful for predicting survival in patients with STS who have metastatic disease at initial presentation at 9 Institutions under the Tokai Musculoskeletal Oncology Consortium.

\section{Patients and Methods}

The Tokai Musculoskeletal Oncology Consortium was formed in 2014 in order to improve the care of patients with musculoskeletal tumors and to improve the knowledge in all aspects of the biology of these tumors, including basic and clinical research. All the physicians of this consortium are specialized in orthopaedic oncology. Between 2008 and 2013, 47 patients were referred for the 
treatment of STS with metastatic disease at initial presentation. Metastatic disease was defined as stage IV using American Joint Committee on Cancer (AJCC) staging system for STS. The cohort included 31 males and 16 females with a mean age of 55 years (range $=20-92$ years). The mean follow-up duration was 24 months (range $=1.5-72.5$ months). The primary tumor sites included the thigh $(n=16)$, lower leg $(n=4)$, retroperitoneal lesions $(n=4)$, buttock $(n=3)$, abdominal wall $(n=3)$, knee $(n=3)$, back $(n=2)$, chest wall $(n=2)$, axillary lesion $(n=2)$, and others $(n=8)$. Pretreatment workup included contrast-enhanced and/or non-contrast-enhanced computed tomography of the lung, abdomen, and pelvis. Blood samples were obtained before treatment in all patients. The hemoglobin $(\mathrm{Hb})$ levels, albumin levels and CRP levels were measured using an auto analyzer as part of a routine clinical examination and were obtained prior to treatment for all patients. According to World Health Organization (WHO) cut-off levels, anaemia was defined as $\mathrm{Hb}$ levels below $13 \mathrm{~g} / \mathrm{dl}$ in males and below $12 \mathrm{~g} / \mathrm{dl}$ in females. Standard levels of CRP were $\leq 0.3 \mathrm{mg} / \mathrm{dl}$ at 7 hospitals, $\leq 0.2 \mathrm{mg} / \mathrm{dl}$ at one hospital and $\leq 0.5 \mathrm{mg} / \mathrm{dl}$ at one hospital.

The high-sensitivity modified GPS (HS-mGPS) was constructed as described previously (1). Briefly, patients with both hypoalbuminemia $(<3.5 \mathrm{~g} / \mathrm{dl})$ and elevated CRP levels $(>0.3 \mathrm{mg} / \mathrm{dl})$ were allocated a score of 2 . Those who had only an elevated CRP levels were allocated a score of 1 . The remaining patients were allocated a score of 0 . This study was approved by the institutional review board at Mie University Hospital.

Statistical analysis. Statistical associations between clinicopathological variables were evaluated using the Mann-Whitney $U$-test and the Kruskal-Wallis test for quantitative data, and the $\chi^{2}$ test for qualitative data. Correlations between continuous factors were tested using Spearman rank correlation analysis. A statistically significant Spearman @ implies a correlation in the population. The survival time was measured from the date of the diagnosis of the primary tumor to the date of last follow-up or death due to sarcoma. Survival curves were constructed using the Kaplan-Meier method. Univariate and multivariate analyses were performed using the Cox proportional hazard model. The variables included in the multivariate analysis were those identified as significant in the univariate analysis. The log-rank test was used to compare survival. A value of $p<0.05$ was considered significant for all statistical analyses. The cutoff values of CAR were determined by Receiver operating characteristics (ROC) curve analyses. All analyses were conducted using the statistical software package Stat View Version 5.0 (SAS Institute, Cary, NC, USA) and EZR (Saitama Medical Center, Jichi Medical University, Saitama, Japan).

\section{Results}

Clinicopathological characteristics. The tumors were histologically classified as follows: 15 undifferentiated pleomorphic sarcomas (UPS), 7 leiomyosarcomas, 6 synovial sarcomas, 5 alveolar soft part sarcomas, 4 liposarcomas, 4 malignant peripheral nerve sheath tumors, and 6 other tumors. The mean primary tumor size at diagnosis was $9.7 \mathrm{~cm}$ (range $=4-25 \mathrm{~cm}$ ). The tumor depth was superficial or deep in 2 and 45 patients, respectively. Primary tumor resection was received in 23 patients, whereas definitive radiotherapy for primary tumor, that included particle-bean therapy was received in 13 patients. Chemotherapy was received in 33
Table I. Clinical characteristics.

\begin{tabular}{|c|c|c|}
\hline \multicolumn{3}{|l|}{ Variables } \\
\hline \multirow[t]{2}{*}{ Age (years) } & Mean & 55 \\
\hline & Range & $20-92$ \\
\hline \multirow[t]{2}{*}{ Gender } & Male & 31 \\
\hline & Female & 16 \\
\hline \multirow[t]{2}{*}{ Depth } & Superficial & 2 \\
\hline & Deep & 45 \\
\hline \multirow[t]{2}{*}{ Primary tumor size $(\mathrm{cm})$} & Mean & 9.7 \\
\hline & Range & $4-25$ \\
\hline \multirow[t]{3}{*}{$\mathrm{CRP}(\mathrm{mg} / \mathrm{dl})$} & Mean & 2.47 \\
\hline & Median & 0.28 \\
\hline & Range & $0.01-32.95$ \\
\hline \multirow[t]{3}{*}{ Hemoglobin (g/dl) } & Mean & 13.1 \\
\hline & Median & 13.6 \\
\hline & Range & $7.9-16.2$ \\
\hline \multirow[t]{3}{*}{ Albumin $(\mathrm{g} / \mathrm{dl})$} & Mean & 4.1 \\
\hline & Median & 4.2 \\
\hline & Range & $2.2-5.1$ \\
\hline \multirow[t]{11}{*}{ Surgery (n) } & Yes & 23 \\
\hline & Surgery+Cx & 11 \\
\hline & Surgery alone & 7 \\
\hline & Surgery+Cx+Rx & 3 \\
\hline & Surgery + Rx & 2 \\
\hline & No & 24 \\
\hline & Cx alone & 10 \\
\hline & $\mathrm{Cx}+\mathrm{Rx}$ & 9 \\
\hline & $\mathrm{Cx}+$ heavy particle therapy & 2 \\
\hline & Rx alone & 2 \\
\hline & None & 1 \\
\hline
\end{tabular}

CRP: C-reactive protein; $\mathrm{Cx}$ : chemotherapy; Rx: radiotherapy.

patients. Age was related to the decision for the primary tumor resection $(p=0.04)$ and administration of chemotherapy $(p=0.01)$. The details of each treatment are shown in Table I. Isolated lung metastasis was observed in 26 patients, whereas lung metastasis with extra-pulmonary metastasis was seen in 16 patients. Isolated liver metastasis and intraabdominal metastasis was seen in one patient, respectively. Although lymph node metastasis was seen in 7 patients, isolated remote lymph node metastasis was seen in 2 patients.

The mean CRP levels was $2.47 \mathrm{mg} / \mathrm{dl}$ (median, $0.28 \mathrm{mg} / \mathrm{dl}$; range $=0.01-32.95 \mathrm{mg} / \mathrm{dl}$ ). The CRP levels could not be measured in three patients because qualitative analysis of CRP was performed in two patients, whose results were negative, and there was no measurementfor one patient. Elevated CRP levels above standard levels at each hospital were seen in 20 patients. The mean $\mathrm{Hb}$ level was $13.1 \mathrm{~g} / \mathrm{dl}$ (median, $13.6 \mathrm{~g} / \mathrm{dl}$; range, 7.9-16.2 g/dl). The mean albumin levels were $4.1 \mathrm{~g} / \mathrm{dl}$ (median, $4.2 \mathrm{~g} / \mathrm{dl}$; range, 2.2-5.1 g/dl). The correlation between the clinical characteristics and CRP levels is shown in Table II. Hb levels (Spearman $\mathrm{Q}=-0.445, p=0.004$ ) and albumin levels (Spearman $\varrho=-0.742, p<0.0001$ ) were 
Table II. Correlation of CRP levels with clinical. variables.

\begin{tabular}{lcc}
\hline Variables & Spearman @ & $p$-Value \\
\hline Age (years) & 0.148 & 0.33 \\
Size $(\mathrm{cm})$ & 0.097 & 0.53 \\
Hemoglobin $(\mathrm{g} / \mathrm{dl})$ & -0.445 & 0.004 \\
Albumin $(\mathrm{g} / \mathrm{dl})$ & -0.742 & $<0.0001$ \\
\hline
\end{tabular}

Table III. Univariate analysis of factors predictive for survival.

\begin{tabular}{lcccc}
\hline Variables & & \multicolumn{2}{c}{ Survival rate $(\%)$} & \multirow{2}{*}{$p$-Value } \\
\cline { 3 - 3 } & $\mathrm{n}$ & 2 years & 3 years & \\
& & & & \\
Gender & 31 & 51.1 & 26.4 & 0.41 \\
$\quad$ Male & 16 & 61.9 & 45.1 & \\
$\quad$ Female & & & & \\
Extra-lung metastasis & 21 & 55.1 & 20.7 & 0.23 \\
$\quad$ Yes & 26 & 59.7 & 43.4 & \\
$\quad$ No & & & & \\
Primary surgical resection & 23 & 63.2 & 51.1 & 0.04 \\
$\quad$ Yes & 24 & 42 & 15.8 & \\
$\quad$ No & & & & \\
Chemotherapy & 33 & 60.2 & 31.1 & 0.63 \\
$\quad$ Yes & 14 & 41.3 & 41.3 & \\
$\quad$ No & & & & \\
Anemia & 13 & 30.6 & 30.6 & 0.04 \\
$\quad$ Yes & 33 & 65.1 & 36.9 & \\
$\quad$ No & & & & \\
Hypoalbuminemia & 6 & 0 & 0 & $<0.0001$ \\
$\quad$ Yes & 40 & 62.3 & 36.8 & \\
$\quad$ No & & & & \\
CRP & 20 & 31.2 & 15.6 & 0.007 \\
$\quad$ Elevated & 26 & 66.8 & 47.1 & \\
$\quad$ Normal & & & & \\
\hline
\end{tabular}

CRP: C-reactive protein.

significantly correlated to CRP levels. Age was not correlated to CRP , Hb and albumin levels.

The HS-mGPS varied from 0 to 2 . A total of 24 patients had a score of 0,15 had a score of 1 and six had a score of 2 (2 patients; incomplete data).

Prognostic factor analyses. At the final follow-up, 5 patients were alive without disease, 14 were alive with disease and 28 patients had deceased. The 2-year and 3-year diseasespecific survival rate was $55.0 \%$ (95\% confidence interval [CI], 40.2\%-69.8\%) and 32.6\% (95\%CI, 17.7\%-47.5\%).

Univariate analyses for disease-specific survival using log rank test confirmed the predictive value of CRP levels $(p=0.007)$, albumin levels $(p<0.0001)$, anemia $(p=0.04)$ and
Table IV. Univariate Cox regression analysis for continuous data.

\begin{tabular}{lccc}
\hline Variables & HR & $95 \% \mathrm{CI}$ & $p$-Value \\
\hline Age (years) & 1.048 & $1.022-1.075$ & 0.0003 \\
Size $(\mathrm{cm})$ & 1.043 & $0.972-1.119$ & 0.24 \\
Hemoglobin $(\mathrm{g} / \mathrm{dl})$ & 0.818 & $0.679-0.985$ & 0.03 \\
Albumin $(\mathrm{g} / \mathrm{dl})$ & 0.229 & $0.123-0.428$ & $<0.0001$ \\
CRP $(\mathrm{mg} / \mathrm{dl})$ & 1.078 & $1.03-1.129$ & 0.001 \\
\hline
\end{tabular}

CRP: C-reactive protein; HR: hazard risk, 95\% CI: 95\% confidential interval.

Table V. Multivariate analysis of predictive factors for survival.

\begin{tabular}{lccc}
\hline Variables & HR & $95 \% \mathrm{CI}$ & $p$-Value \\
\hline Age (years) & 1.061 & $1.029-1.095$ & 0.002 \\
Primary surgical resection & 1.274 & $0.467-3.471$ & 0.64 \\
Hemoglobin (g/dl) & 1.012 & $0.693-1.477$ & 0.95 \\
Albumin (g/dl) & 0.257 & $0.084-0.789$ & 0.02 \\
CRP (mg/dl) & 1.108 & $1.029-1.194$ & 0.007 \\
\hline
\end{tabular}

CRP: C-reactive protein; HR: hazard risk; 95\% CI: 95\% confidential interval.

primary tumor resection $(p=0.04)$ (Table III). Univariate Cox regression analyses of factors as continuous variables showed the predictive value of CRP levels ( $p=0.001$, hazard ratio (HR); $1.078,95 \% \mathrm{CI} ; 1.030-1.129)$, Hb level ( $p=0.03$, HR; 0.818, 95\%CI; 0.679-0.985), age ( $p<0.0001$, HR; 1.048 , $95 \% \mathrm{CI} ; 1.022-1.751)$ and albumin levels $(p<0.0001, \mathrm{HR}$; $0.229,95 \% \mathrm{CI} ; 0.123-0.428$ ) (Table IV). In the multivariate analysis, CRP ( $p=0.007$, HR; 1.108, 95\%CI; 1.029-1.194), age $(p=0.0002, \mathrm{HR} ; 1.061,95 \% \mathrm{CI} ; 1.029-1.095)$ and albumin ( $p=0.02$. HR; $0.257,95 \% \mathrm{CI} ; 0.084-0.789)$ were independent prognostic factors for disease-specific survival (Table V). The 2- and 3-year disease-specific survival rates in patients with elevated level of CRP were $31.2 \%$ (95\% CI, 9.6\%-52.7\%) and $15.6 \%$ (95\% CI, 0\%-34.3\%), respectively, compared with $66.8 \%$ (95\%CI, $47.9 \%-85.7 \%$ ) and $47.1 \%$ (95\%CI, 26\%-68.2\%) in those with normal level of CRP ( $p=0.007, \log$ rank test) (Figure 1). The 6 patients with hypoalbuminemia had deceased from their disease within 15 months. When patients were divided into three groups according to the HS-mGPS, those with a score of 2 had a poorer survival than those with a score of $0(p<0.0001, \log$ rank test). The 2- and 3-year survival rates were $0 \%$ for those with a score of 2, compared with $63.7 \%$ (95\% CI, $43.6 \%$ $83.9 \%$ ) and $48.1 \%$ (95\% CI, 26.5\%-69.8\%), respectively, for those with a score of 0 . Those with a score of 1 also had a poorer survival than those with a score of $2(p=0.003, \log$ rank test; $49.5 \%$ (95\%CI, 22.6\%-76.4\%) and $20.6 \%$ (95\%CI, 


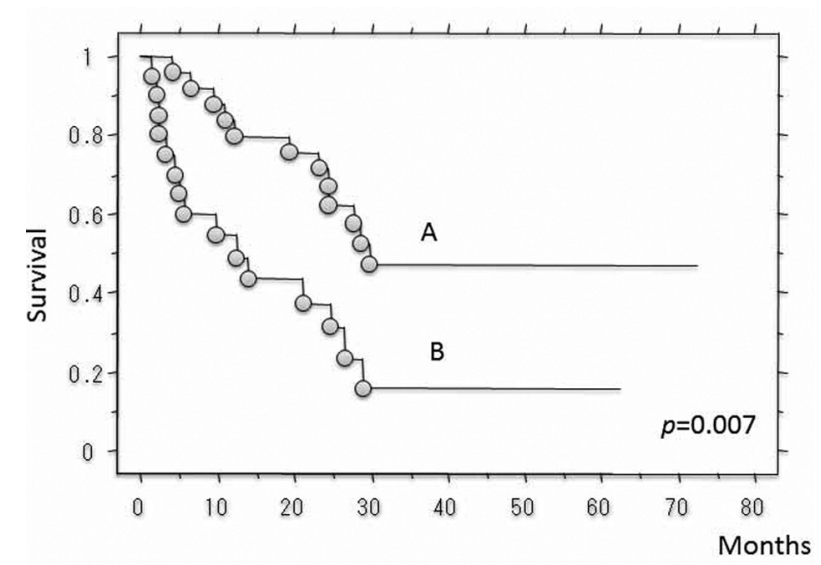

Figure 1. Kaplan-Meier curve showing the survival rates of the patients with soft-tissue sarcoma who have metastatic disease at initial presentation (A: patients with normal CRP levels; B: patients with elevated CRP levels).

$0 \%-44.9 \%)$. There was no significant difference in the prognosis between patients with a score of 0 and those with a score of 1 ( $p=0.09, \log$ rank test) (Figure 2).

Finally, we created a ROC curve that showed appropriate threshold of CAR to identify if patients are at risk of death. On ROC analysis, a value of 0.143 was an appropriate threshold. When we divided two groups according to the value of CAR, the patients with higher value of CAR had significantly poorer survival (20\% at 2 years, $95 \% \mathrm{CI}$; $0 \%-40.2 \%)$, compared with those with lower value of CAR $(63.8 \%$ at 2 years, $95 \%$ CI; $44.7 \%-82.9 \%, p=0.002$ ) (Figure 3).

\section{Discussion}

There is little information concerning prognostic factors for survival in patients with STS who have metastatic disease at initial presentation, because decision making is complex, depending on diverse presentations and histologies (13).

In the present study, we demonstrated that CRP levels and albumin levels were associated with disease-specific survival in patients with STS who have metastatic disease at initial presentation. No studies have, so far, shown the relationship between those markers and survival of these patients based on a multivariate analysis, although our previous study has shown a role of CRP in predicting post-metastatic survival of patients with metastatic bone sarcomas and STS, which included 22 patients who had metastasis at initial presentation (14). CRP has consistently been elevated in more advanced disease and found to be a predictor of poor outcome in advanced cancer patients (11, 15-17). In fact, in the present study, elevated CRP levels were found in $43.5 \%$ of patients. This ratio was higher than our previous studies where only

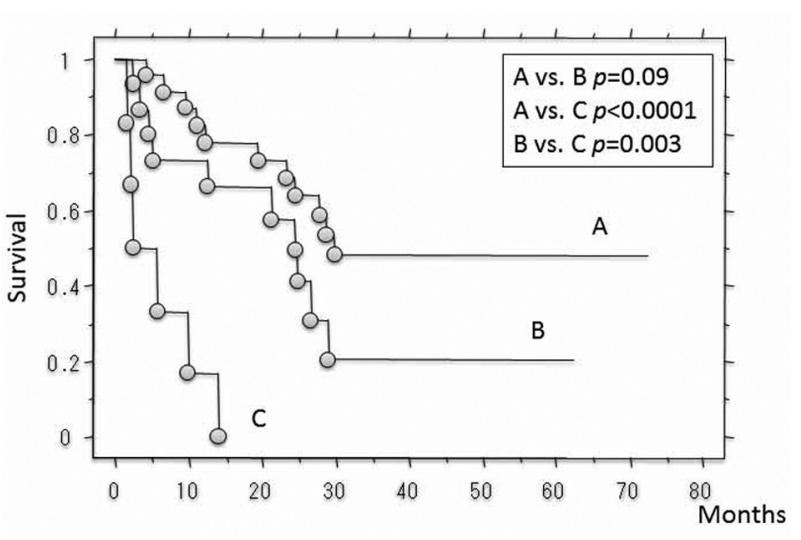

Figure 2. Kaplan-Meier curve showing the survival rates which are divided into 3 groups according to high-sensitivity Glasgow prognostic score (A: patients with score of $0 ; B$ : patients with score of $1 ; C$; patients with score of 2 ).

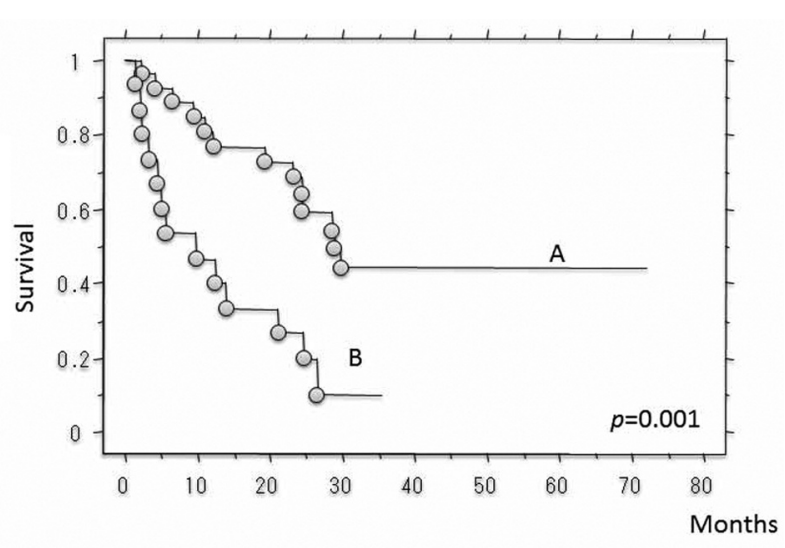

Figure 3. Kaplan-Meier curve showing the survival rates which are divided into 2 groups according to $C$-reactive potein/albumin ratio ( $A$; patients with $C A R>0.143$; B: patients with $C A R<0.143$ ).

18 to $22 \%$ of the patients with non-metastatic STS had elevated CRP levels $(1,6)$. In the present study, CRP levels were significantly negatively correlated with $\mathrm{Hb}$ and albumin levels. CRP and albumin are closely correlated with inflammation. Several studies have previously demonstrated that high levels of cytokine interleukin-6 (IL-6) contribute to the development of hypoalbuminemia and elevated CRP levels $(1,18)$. However, in the present study, only $13 \%$ of the patients had hypoalbuminemia (albumin $<3.5 \mathrm{~g} / \mathrm{dl}$ ) which led to a a score of 2 when using HS-mGPS. Therefore, albumin levels may be useful as quantitative data and CAR was associated with outcomes in patients with STS who have metastatic disease at initial presentation although HS-mGPS 
was also a useful scoring system. New aggressive treatments should be considered for the patients with higher risk of mortality in the future. Age was also a prognostic factor for survival in the present study. Generally, physicians often hesitate to perform systemic chemotherapy due to the risk of adverse events. In the present study, age was related to the decision of primary tumor resection and administration of chemotherapy, although chemotherapy was not a prognostic factor for survival.

There are a few limitations in the present study. Firstly, the presence of systemic diseases may be associated with possible higher levels of CRP and NLR. Although we performed blood examinations and CT scan of the lung, abdomen and pelvis because of the decision of the AJCC staging, all inflammatory conditions were not detected. The retrospective design and small number of patients of the study were also limitations. However, we believe that the measurement of CRP levels and albumin levels are a useful method for recognizing patients who have a greater risk of mortality.

\section{Conclusion}

CRP and albumin levels could be useful prognostic markers for predicting survival in patients with STS who have metastatic disease at initial presentation, as shown in this multicenter study.

\section{Conflicts of Interest}

There are no conflicts of interest.

\section{References}

1 Nakamura T, Matsumine A, Asanuma K, Matsubara T and Sudo A: The value of the high-sensitivity modified Glasgow prognostic score in predicting the survival of patients with a soft-tissue sarcoma. Bone Joint J 97-B: 847-852, 2015.

2 Choi ES, Kin HS and Han I: Elevated preoperative systemic inflammatory markers predict poor outcome in localized soft tissue sarcoma. Ann Surg Oncol 21: 778-785, 2014.

3 Szkandera J, Gerger A, Liegl-Atzwanger B, Absenger G, Stotz M, Samonigg H, Maurer-Ertl W, Stojakovic T, Ploner F, Leithner $\mathrm{A}$ and Pichler M: Validation of the prognostic relevance of plasma C-reactive protein levels in soft-tissue sarcoma patients. Br J Cancer 109: 2316-2322, 2013.

4 Li Y, Liu X, Zhang J and Yao W: Prognostic role of elevated preoperative systemic inflammatory markers in localized soft tissue sarcoma. Cancer Biomark 16: 333-342, 2016.

5 Nakamura T, Grimer R, Gaston C, Francis M, Charman J, Graunt P, Uchida A, Sudo A and Jeys L: The value of C-reactive protein and comorbidity in predicting survival of patients with high grade soft tissue sarcoma. Eur J Cancer 49: 377-385, 2013.

6 Nakamura T, Matsumine, Matsubara T, Asanuma K, Uchida A and Sudo A: Clinical significance of pretreatment serum Creactive protein level in soft tissue sarcoma. Cancer 118: 10551081, 2012.
7 Panotopoulos J, Posch F, Alici B, Funovics P, Stihsen C, Amann G, Brodowicz T, Windhager R and Ay C: Hemoglobin, alkali phosphatase, and C-reactive protein predict the outcome in patients with liposarcoma. J Orthop Res 33: 765-770, 2015.

8 Nakamura T, Grimer R, Gaston C, Carter S, Tillman R, Abudu A, Jeys L and Sudo A: The relationship between pretreatment anaemia and survival in patients with adult soft tissue sarcoma. J Orthop Sci 18: 987-993, 2013.

9 Kinoshita A, Onoda H, Imai N, Iwaku A, Oishi M, Tanaka K, Fushiya N, Koike K, Nishino $\mathrm{H}$ and Matsushima M: The Creactive protein/albumin ratio, a novel inflammation-based prognostic score, predicts outcomes in patients with hepatocellular carcinoma. Am Surg Oncol 22: 803-810, 2015.

10 Ishizuka M, Nagata H, Takagi K, Iwasaki Y, Shibuya N and Kubota K: Clinical significance of the C-reactive protein to albumin ratio for survival after surgery for colorectal cancer. Ann Surg Oncol 23: 900-907, 2016.

11 Forrest LM, McMillan DC, McArdle CS, Angerson WJ and Dunlop DJ: Evaluation of cumulative prognostic scores based on the systemic inflammatory response in patients with inoperable non-small-cell lung cancer. Br J Cancer 89: 10281030, 2003.

12 Proctor MJ, Horgan PG, Talwar D, Fletcher CD, Morrison DS and McMillan DC: Optimization of the systemic inflammationbased Glasgow prognostic score: a Glasgow inflammation Outcome Study. Cancer 119: 2325-2332, 2013.

13 ESMO/ European Sarcoma Network Working Group: Soft tissue and visceral sarcomas: ESMO Clinical Practice Guildelines for diagnosis, treatment and follow-up. Ann Oncol 25(Suppl 3): 102$112,2014$.

14 Nakamura T, Matsumine A, Asanuma K, Matsubara T and Sudo A: The Role of C-reactive protein in predicting post-metastatic survival of patients with metastatic bone and soft tissue sarcoma. Tumor Biol 36: 7515-7520, 2015.

15 Woo Y, Hyung WJ, Obama K, Kim HI, Pak KH, Son T and Noh $\mathrm{SH}$ : Elevated high-sensitivity C-reactive protein, a marker of advanced stage gastric cancer and postgastrectomy disease recurrence. J Surg Oncol 105: 405-409, 2012.

16 Ito H, Shioi K, Murakami T, Takizawa A, Sano F, Kawahara T, Mizuno N, Makiyama K, Nagaigawa N, Kishida T, Miura T, Kubota $\mathrm{Y}$ and Yao M: C-reactive protein in patients with advanced metastatic renal cell carcinoma: usefulness in identifying patients most likely to benefit from initial nephrectomy. BMC Cancer 12: 337, 2012.

17 Zeng YC, Xue M, Chi F, Xu ZG, Fan GL, Wu R, Fan YC, Zhong WZ, Wang SL, Zhang XY, Wu LN, Chen XD, Jin XY, Duan QY, Xu R, Chen W, Qian HC and Xiao YP: C-reactive protein level predicts prognosis in patients with locoregionally advanced laryngeal carcinoma treated with chemoradiotherapy. Tumor Biol 33: 891-895, 2012.

18 McMillan DC, Watson WS, O'Gorman P, Preston T, Scott HR and McArdle CS: Albumin concentrations are primarily determined by the body cell mass and the systemc inflammatory response in cancer patients with weight loss. Nutr Cancer 38: 210-213, 2001 